\title{
Note
}

\section{Isolation and identification of oryzamutaic acids $A$ and $D$ from an Oryza sativa spontaneous mutant with yellow endosperm}

\author{
Hiroshi Nakano*1), Katsunori Tamura1), Makoto Sakai'), Naoto Ooka ${ }^{2)}$, Makoto Arakawa ${ }^{2)}$, Kenji Yagasaki²), \\ Toyotaka Minoda ${ }^{2)}$, Satoshi Noda ${ }^{2}$ and Mamoru Arai ${ }^{2)}$ \\ 1) National Agricultural Research Center for Kyushu Okinawa Region, 496 Izumi, Chikugo, Fukuoka 833-0041, Japan \\ 2) Saitama Prefectural Agriculture and Forestry Research Center, 1372 Kubojima, Kumagaya, Saitama 360-0831, Japan
}

Oryzamutaic acids $\mathrm{A}$ and $\mathrm{D}$, alkaloids with a novel type of nitrogen-containing heterocyclic ring system, which had previously been isolated only from the brown rice (husked rice) of Hatsuyamabuki, an Oryza sativa artificial mutant cultivar with yellow endosperm, were isolated from the brown rice of Musashino 20, an Oryza sativa spontaneous mutant line with yellow endosperm. The concentrations of oryzamutaic acids $\mathrm{A}$ and $\mathrm{D}$ in the brown rice of Musashino 20 were similar to those of Hatsuyamabuki, respectively. These results suggest that oryzamutaic acid A may play an important role in the yellow color of the brown rice of Musashino 20.

Key Words: Oryza sativa, gramineae, alkaloid, oryzamutaic acids A and D.

\section{Introduction}

Rice (Oryza sativa) is the most important crop in Asia. Artificial mutation by means of radiation and chemicals has been used to improve the yield and quality of rice (Amano 2001). The rare rice cultivar Hatsuyamabuki, which has yellow endosperm, was selected from the progeny obtained by treatment of the rice cultivar Kinuhikari with $\gamma$-rays at the National Agricultural Research Center for Kyushu Okinawa Region (Kaji et al. 2010). In previous study, we isolated oryzamutaic acids A-J, alkaloids with a novel nitrogencontaining heterocyclic ring system, from the yellow endosperm (polished rice) of Hatsuyamabuki (Nakano et al. 2009, 2010a, 2010b). Oryzamutaic acids A-C are yellow, but oryzamutaic acids D-J are colorless. Among oryzamutaic acids present in the endosperm of Hatsuyamabuki, oryzamutaic acids $\mathrm{A}$ and $\mathrm{D}$ are the most prevalent.

Recently, Musashino 20, a spontaneous mutant rice line that also has yellow endosperm, was selected from the progeny of the rice cultivar Sainokagayaki at the Saitama Prefectural Agriculture and Forestry Research Center (Ooka et al. 2010). However, the yellow pigments from Musashino 20 have not yet been isolated. In this study, we focused on the yellow pigments in the brown rice of Musashino 20.

Communicated by T. Anai

Received October 27, 2010. Accepted January 5, 2011.

*Corresponding author (e-mail: nakanohr@affrc.go.jp)

\section{Materials and Methods}

General experimental procedures

HRESIMS spectra were recorded on a Bruker MicrOTOF spectrometer.

\section{Plant materials}

The rice (Oryza sativa) grains of a line Musashino 20 and a cultivar Sainokagayaki were obtained from the Saitama Agricultural Research Center in 2007. The rice grains of cultivars Hatsuyamabuki and Kinuhikari were obtained from the National Agricultural Research Center for Kyushu Okinawa Region in 2007. All of the grains obtained from these research centers were husked.

\section{Extraction and isolation}

The brown rice $(100 \mathrm{~g})$ of Musashino 20 was extracted with $300 \mathrm{~mL}$ of aq. $\mathrm{MeOH}\left(\mathrm{MeOH} / \mathrm{H}_{2} \mathrm{O}, 1: 9\right)$ for 5 days at $25^{\circ} \mathrm{C}$. The extract $(4 \mathrm{~g})$ was subjected to $\mathrm{C}_{18}$ column chromatography $\left(\mathrm{MeOH} / \mathrm{H}_{2} \mathrm{O}, 0: 1 \rightarrow 1: 0\right)$ followed by $\mathrm{C}_{18}$ HPLC to yield oryzamutaic acids A ( $0.1 \mathrm{mg}, 0.0001 \%$ yield) and $\mathrm{D}(0.1 \mathrm{mg}, 0.0001 \%$ yield $)$ as yellow and colorless powder, respectively.

Determination of the concentrations of oryzamutaic acids $A$ and $D$

The brown grain $(5 \mathrm{~g})$ was extracted with $25 \mathrm{~mL}$ of aq. $\mathrm{MeOH}\left(\mathrm{MeOH} / \mathrm{H}_{2} \mathrm{O}, 1: 4\right)$ for 1 day at $25^{\circ} \mathrm{C}$, and then was homogenized and extracted for 1 day at $25^{\circ} \mathrm{C}$. Fifty $\mathrm{mL}$ of 
aq. $\mathrm{MeOH}\left(\mathrm{MeOH} / \mathrm{H}_{2} \mathrm{O}, 1: 4\right)$ was added to the solution, which was then centrifuged at $3,500 \mathrm{~g}$ for $10 \mathrm{~min}$ at $25^{\circ} \mathrm{C}$. The supernatant was filtered and concentrated. Seventy five $\mathrm{mL}$ of aq. $\mathrm{MeOH}\left(\mathrm{MeOH} / \mathrm{H}_{2} \mathrm{O}, 4: 1\right)$ was added to the concentrate, which was centrifuged at $3,500 \mathrm{~g}$ for $10 \mathrm{~min}$ at $25^{\circ} \mathrm{C}$. The supernatant was filtered and concentrated. One $\mathrm{mL}$ of $\mathrm{H}_{2} \mathrm{O}$ was added to the concentrate, which was then subjected to $\mathrm{C}_{18}$ HPLC (ODS-80Ts, Tosoh, $4.6 \times 250 \mathrm{~mm}$; eluent $\mathrm{MeOH} / \mathrm{H}_{2} \mathrm{O}, 0: 1 \rightarrow 3: 7$; flow rate $0.8 \mathrm{~mL} / \mathrm{min}$; UV detection at 395 and $360 \mathrm{~nm}$ ). The amounts of oryzamutaic acids $A$ and D were calculated from standard curves by measurement of the areas of the peaks for them. This experiment was replicated three times.

\section{Results and Discussion}

We compared HPLC chromatograms of the brown rice extracts of Musashino 20 and Sainokagayaki (Fig. 1). In the extract of Musashino 20, two major peaks were detected, one at $395 \mathrm{~nm}$ and the other at $360 \mathrm{~nm}$. However, in Sainokagayaki, no peaks were detected at either wavelength. The compounds corresponding to the two peaks Musashino 20 were isolated. The compound corresponding to the peak at $395 \mathrm{~nm}$, which had the same HPLC retention time as oryzamutaic acid A (Fig. 2), had the molecular formula $\mathrm{C}_{23} \mathrm{H}_{32} \mathrm{~N}_{4} \mathrm{O}_{6}$, established by HRESIMS [ $\mathrm{m} / \mathrm{z} 459.2253$ (M$\left.\mathrm{H})^{-}, \Delta+1.5 \mathrm{mmu}\right]$, which is the same as that of oryzamutaic acid A (Nakano et al. 2009). The compound corresponding to the peak at $360 \mathrm{~nm}$, which had the same HPLC retention time as oryzamutaic acid D (Fig. 2), had the molecular formula, $\mathrm{C}_{17} \mathrm{H}_{25} \mathrm{~N}_{3} \mathrm{O}_{4}$, established by HRESIMS [ $\mathrm{m} / z 334.1805$ $(\mathrm{M}-\mathrm{H})^{-}, \Delta+4.4 \mathrm{mmu}$, which is the same as those of oryzamutaic acids D-G (Nakano et al. 2010a). Oryzamutaic acids $\mathrm{E}-\mathrm{G}$ had shorter retention times than oryzamutaic acid D. Among oryzamutaic acids present in the endosperm of Hatsuyamabuki, oryzamutaic acids $\mathrm{A}$ and $\mathrm{D}$ are the most prevalent (Nakano et al. 2009, 2010a, 2010b). These results indicate that the brawn rice of Musashino 20, like that of Hatsuyamabuki, contained oryzamutaic acids A and D.

We determined the concentrations of oryzamutaic acids A and D (Fig. 2) in the brown rice of Musashino 20 and Hatsuyamabuki (Table 1). By subjecting the brown rice extracts Musashino 20 and Hatsuyamabuki to HPLC and measuring the peak area of the chromatograms, we estimated the concentrations of oryzamutaic acid A in Musashino 20 and Hatsuyamabuki to be 2.54 and $2.97 \mathrm{mg} / \mathrm{kg}$, respectively, and the concentrations of oryzamutaic acid D to be 3.37 and $3.26 \mathrm{mg} / \mathrm{kg}$, respectively; that is, the concentrations of oryzamutaic acids $\mathrm{A}$ and $\mathrm{D}$ in the brown rice of Musashino 20 were similar to those of Hatsuyamabuki, respectively. These results suggest that oryzamutaic acid A may play an important role in the yellow color of the brown rice of Musashino 20 as well as Hatsuyamabuki.

Kaji et al. (2010) reported that the spectrophotometer " $b$ *" value representing the level of yellow is only slightly higher in the brown rice of Hatsuyamabuki (19.17) than in
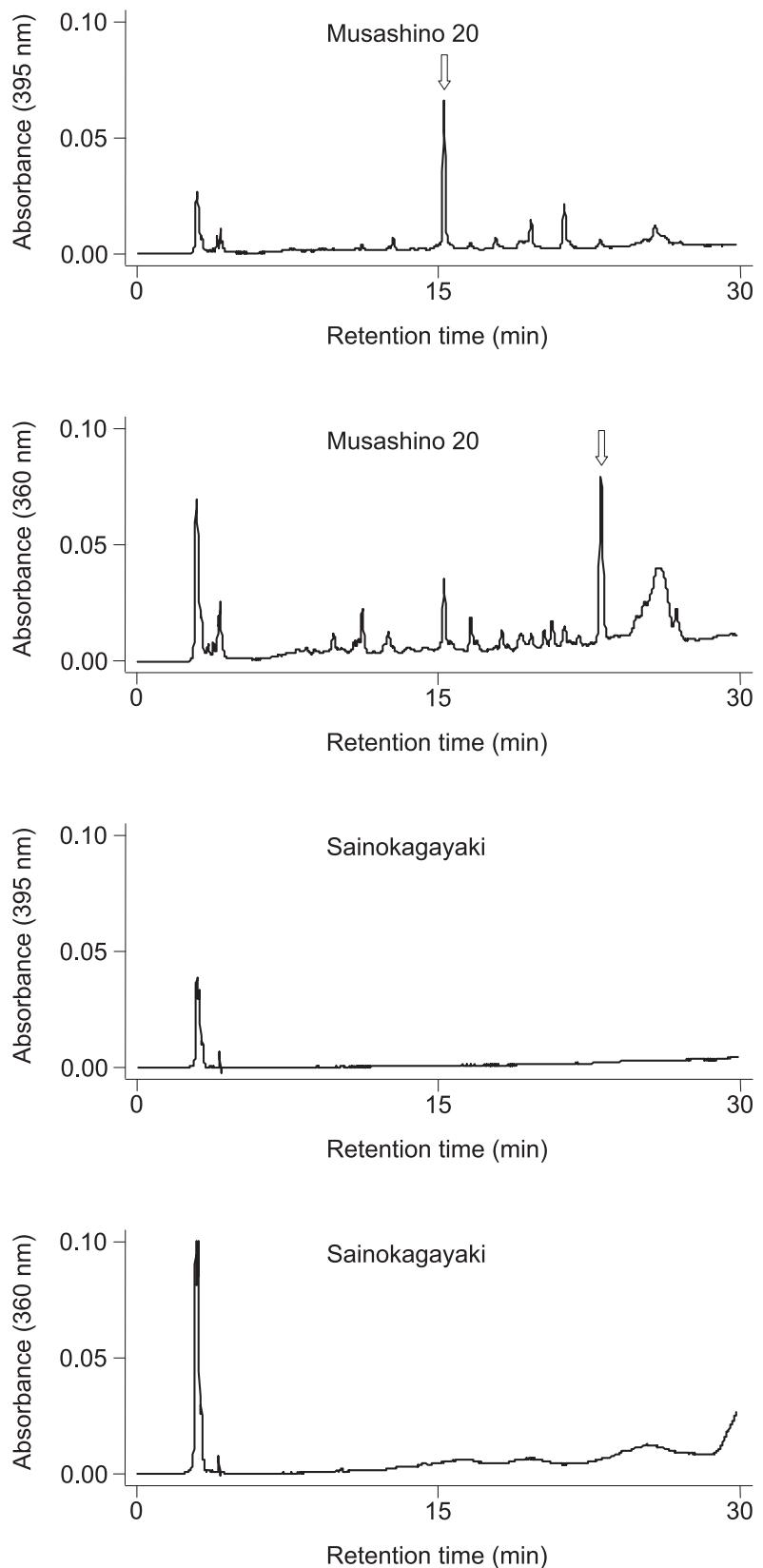

Fig. 1. HPLC chromatograms of brown rice extracts of Musashino 20 and Sainokagayaki. Arrows indicate major peaks.

that of Kinuhikari (17.69), but the value is much higher in the endosperm of Hatsuyamabuki (19.48) than in that of Kinuhikari (9.61). Thus, although distinguishing the difference in endosperm color between Musashino 20 and Sainokagayaki and between Hatsuyamabuki and Kinuhikari could be expected to be easy, distinguishing the color difference in the brown rice of these pairs of cultivars might be difficult. In the initial selection stage of rice breeding, although many progeny of various cultivars and lines are selected, the endosperm color of their progeny is hardly examined. Therefore, the mutation with yellow endosperm except for Musashino 20 and Hatsuyamabuki might have occurred spontaneously or artificially over the course of a long rice 

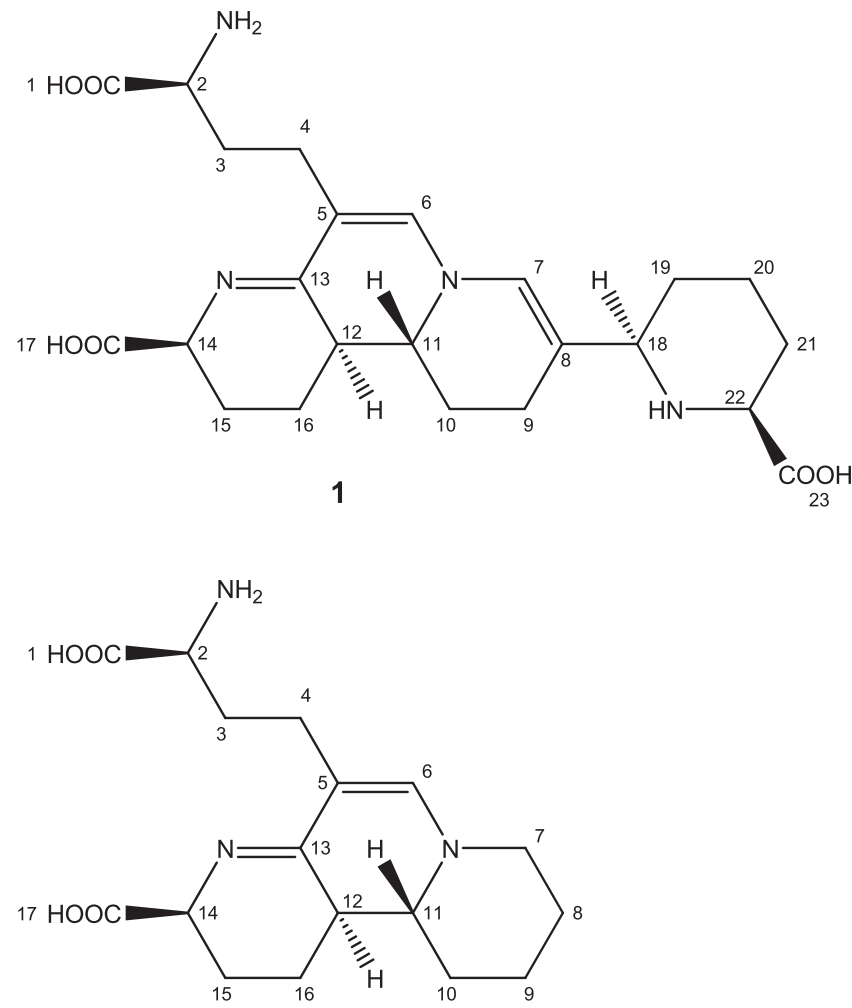

2

Fig. 2. Structure of oryzamutaic acid A (top) and D (bottom).

Table 1. Concentrations of oryzamutaic acids A and D in the brown rice of Musashino 20 and Hatsuyamabuki

\begin{tabular}{lcc}
\hline \hline Line or cultivar & oryzamutaic acid A & oryzamutaic acid D \\
\hline & & $\mathrm{mg} / \mathrm{kg}$ \\
Musashino20 & $2.54 \pm 0.03$ & $3.37 \pm 0.22$ \\
Hatsuyamabuki & $2.97 \pm 0.10$ & $3.26 \pm 0.04$ \\
\hline
\end{tabular}

Means \pm SE from three replicates. breeding history but have gone undetected. Linkage analysis of loci and identification of genes controlling the biogenetic pathway of oryzamutaic acids in these mutants should be conducted.

\section{Acknowledgements}

The authors thank Dr. Masahiro Okamoto (National Agricultural Research Center for Kyushu Okinawa Region) for his valuable suggestions and Ms. Fujiko Komiya (National Agricultural Research Center for Kyushu Okinawa Region) for her valuable help and cooperation. The authors also thank Dr. Tomoyuki Oki (National Agricultural Research Center for Kyushu Okinawa Region) for his assistance with MS measurements.

\section{Literature Cited}

Amano,E. (2001) Mutation breeding in the world as seen in the databases. Gamma Field Symp. 40: 39-51.

Kaji, R. M. Okamoto, M. Sakai, R. Mizobuchi, K. Tamura, H. Hirabayashi, Y.Tamura, S.Fukaura, T.Tomimatsu and H.Nakano (2010) "Hatsuyamabuki", A new rice variety with yellow endosperm derived from gamma ray mutation. Breed. Res. 12: 54-58.

Nakano,H., S.Kosemura, T.Suzuki, R.Kaji, M.Sakai and K.Hirose (2009) Oryzamutaic acid A, a novel yellow pigment from an Oryza sativa mutant with yellow endosperm. Tetrahedron Lett. 50: 20032005.

Nakano,H., S.Kosemura, M.Yoshida, T.Suzuki, R.Iwaura, R.Kaji, M. Sakai and K.Hirose (2010a) Oryzamutaic acids B-G, new alkaloids from an Oryza sativa mutant with yellow endosperm. Tetrahedron Lett. 51: 49-53.

Nakano,H., S.Kosemura, M.Yoshida, R.Iwaura, T.Suzuki, R.Kaji and M. Sakai (2010b) Oryzamutaic acids H-J, new alkaloids from an Oryza sativa mutant with yellow endosperm. Tetrahedron Lett. 51: 4953-4956.

Ooka,N., M.Arakawa, K. Yagasaki, T.Minoda, S.Noda and M.Arai (2010) Breeding of a new rice cultivar "Musashino No. 20" of yellow endosperm by natural mutation. Breed. Res. 12 (Extra issue 1), 196. 